\title{
Preparation of mixed matrix membrane using cellulose acetate incorporated with synthesized KIT-6 silica
}

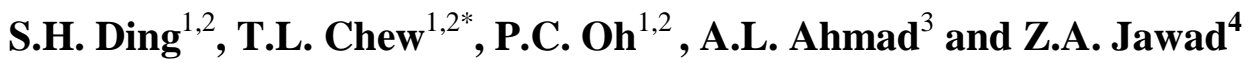 \\ ${ }^{1}$ Department of Chemical Engineering, Universiti Teknologi PETRONAS, \\ 32610 Seri Iskandar, Perak, Malaysia, \\ ${ }^{2} \mathrm{CO}_{2}$ Research Centre (CO2RES), Institute of Contaminant Management, Universiti Teknologi \\ PETRONAS, 32610 Seri Iskandar, Perak, Malaysia. \\ *Email: thiamleng.chew@utp.edu.my \\ Phone: +605-3687626 \\ ${ }^{3}$ School of Chemical Engineering, Engineering Campus, Universiti Sains Malaysia, \\ 14300 Nibong Tebal, Pulau Pinang, Malaysia. \\ ${ }^{4}$ Curtin University Malaysia, Faculty of Engineering and Science, Chemical Engineering \\ Department, 250CDT, 98009 Miri, Sarawak, Malaysia.
}

\begin{abstract}
There is increasing interest among researchers to develop Mixed Matrix Membranes (MMMs), by incorporating fillers in polymer membranes. However, these membranes always suffer from a trade-off between permeability and selectivity as proven by Robeson in upper bound curves developed in gas separation applications. In current project, mesoporous silica, KIT-6 was synthesized and followed by incorporation of KIT- 6 as filler into cellulose acetate (CA) matrix to form MMMs. The fabrications of MMMs were done by using dry phase inversion method. The KIT-6 loadings in the MMMs were varied from 2 to $10 \mathrm{wt} \%$. The properties of KIT- 6 and membranes were characterized with Scanning electron microscopy (SEM), Fourier transform infrared (FTIR), X-ray diffraction (XRD) and thermal gravimetric analysis (TGA). The effect of KIT-6 loadings on the properties of the formed MMMs was investigated. XRD and FTIR results suggested that KIT-6 mesoporous silica is successfully synthesized. The TGA curve indicate the overall weight loss of $3.02 \%$ for KIT-6 and 72.29-86.77 \% for all the membranes. The successful incorporation of silica particles into CA polymer matrix is confirmed by FTIR spectrum while MMMs images from SEM suggested that KIT-6 silica powder could embed well with CA polymer matrix. Defect-free MMMs could be fabricated and potential to be use in future especially in gas separation.
\end{abstract}

Keywords: KIT-6, CA; mixed matrix membrane; dry phase inversion.

\section{INTRODUCTION}

In recent years, polymer membrane getting attraction especially in the field of separation technology. The properties and chemical structure of membranes enable it to be fabricated to fit the special applications for examples in gas separation and water purification [1]. Besides, membrane technology was getting important especially in gas separation industry due to it possess several advantages like simple and energy friendly over conventional methods such as cryogenic distillation and absorption processes [2]. The swift surge in global warming and its adverse effects on the environment have become a serious issue across the globe even on the marine ecosystem [3]. The increasing concentration carbon dioxide $\left(\mathrm{CO}_{2}\right)$ and other greenhouse 
gases in the atmosphere is the main cause for rapid growth in global warming. Therefore, removal of $\mathrm{CO}_{2}$ from gas stream, such as natural gas stream, is one of the major concerns worldwide nowadays. Besides, it is also important to remove $\mathrm{CO}_{2}$ from natural gas to improve its calorific value. Natural gas is one type of energy sources and it is essential because natural gas featuring high calorific value, low pollution and high efficiency [4]. The major component in natural gas is methane which is typically $75-90 \%$ of overall mass and other hydrocarbons, like butane, propane and ethane. Some undesirable impurities also can be found in the gas, such as hydrogen sulfide, carbon dioxide $\left(\mathrm{CO}_{2}\right)$, nitrogen, and water [4].

In the searching of technology to remove $\mathrm{CO}_{2}$, membrane technology has emerged and marked as one of the promising technologies to eliminate $\mathrm{CO}_{2} \cdot \mathrm{CO}_{2}$ separation by using membrane technology has increased tremendously since their first application in 1981 [5]. Membrane technology exhibits operational flexibility, cheap, and small foot-print [6,7]. Some examples of polymer used to manufacture membranes are cellulose acetate (CA), polysulfone, polyimide, and polycarbonates. Due to the high solubility of $\mathrm{CO}_{2}$ within the $\mathrm{CA}$-polymer matrix, CA membranes have been used commercially for many gas separation applications among these organic materials [5].

Nevertheless, Robeson has introduced an "upper bound trade-off" line between selectivity and permeability [8,9]. This upper bound trade-off cannot be overcome by conventional polymer membrane materials. Thus, there are some technical limitations by using bare polymers as membranes. In this case, works have been reported by incorporating different type of inorganic materials, as fillers, into the polymer matrix, producing Mixed Matrix Membranes (MMMs) in order to overcome Robeson's upper-bound trade-off [8].

Inorganic materials, for instances, silica, zeolites, carbon molecular sieves, mesoporous molecular sieves, carbon nanotubes, have been introduced as filler into polymer matrix to produce MMMs [10]. The quality of the interface between the filler and the polymer is the main concern on the success of the MMMs. Searching for suitable filler offering good quality of interface with the polymer phase during MMMs fabrication still remain research challenge nowadays. Among these inorganic materials, mesoporous silica shows great potential as filler in fabricating MMMs [10]. KIT-6 (KIT: Korea Advanced Institute of Science and Technology), one of the example of mesoporous silica with large pore size has attracted the attention of researches for the studies in gas separation. KIT-6 was build up from bicontinuous cubic structure of Ia3d symmetry. The pore diameters of the KIT-6 usually ranging from 5-15 nm and because of these large pore size, KIT- 6 had granted with interpenetrating cylindrical pore system [8].

In current project, KIT-6 was synthesized. MMMs were prepared by incorporating pristine KIT-6 into CA matrix. So far, there is still no reported study on preparation of MMMs by incorporating KIT-6 into CA matrix. It is the objective of the current study to investigate the effect of KIT-6 loading on the properties and structure of the KIT-6/CA MMMs. The synthesized KIT-6 and prepared MMMs were characterized using different analytical techniques.

\section{METHODS AND MATERIALS}

\section{Preparation of KIT-6 Silica}

KIT-6 mesoporous silica is produced according to the procedures reported previously by Zamani et al. [11] with some modifications. KIT-6 was synthesized in acidic conditions using a mixture of Pluronic P123 triblock copolymer $\left(\mathrm{EO}_{20} \mathrm{PO}_{70} \mathrm{EO}_{20}\right)$ and butanol. P123 is dissolved in distilled water and concentrated $\mathrm{HCl}(37 \%)$. After complete dissolving $\mathrm{P} 123$ with stirring at $35^{\circ} \mathrm{C}$, butanol is added to the solution while stirring for 1 hour. Then, tetraethyl orthosilicate (TEOS) is 
added and stirred for 24 hours at the same temperature. The mixture is hydrothermally treated at $100^{\circ} \mathrm{C}$ for 24 hours under static conditions. After hydrothermal treatment, the resultant mixture is filtered, washed at room temperature with deionized water, and dried in oven at $100^{\circ} \mathrm{C}$ overnight. After drying, the sample is calcined at $550^{\circ} \mathrm{C}$ for 6 hours. The mole ratio resultant mixture is $\mathrm{P} 123: \mathrm{H}_{2} \mathrm{O}: \mathrm{HCl}: \mathrm{BuOH}: \mathrm{TEOS}=0.013: 144: 3.77: 1: 0.76$. Figure 1 shows teflon lined stainless steel vessel for preparation of KIT-6.

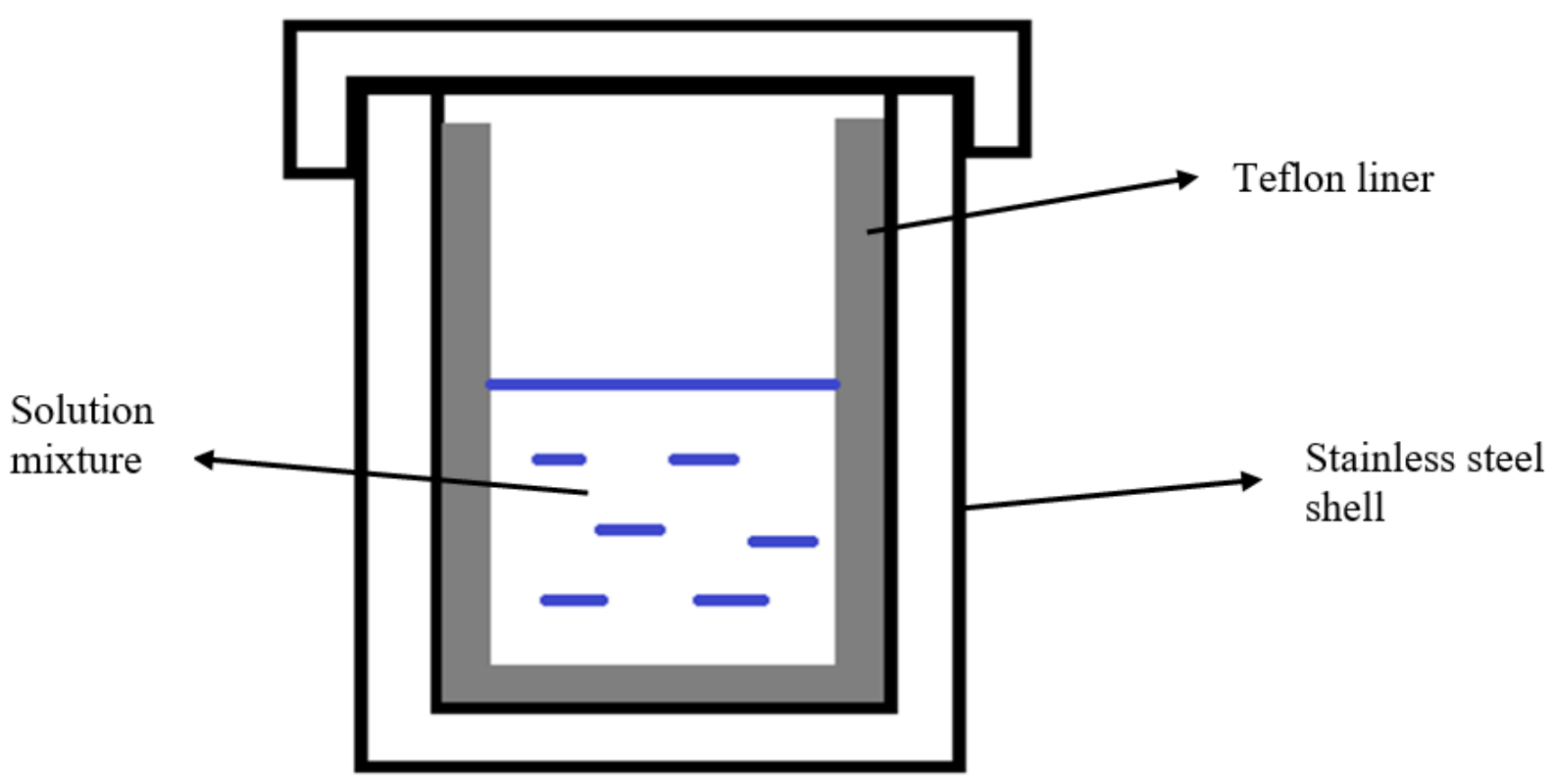

Figure 1. Teflon lined stainless steel vessel for preparation of KIT-6.

\section{Membrane Preparation}

Preparation of MMMs and pure cellulose acetate (CA) membrane is conducted following procedures reported previously by Kim et al. [12] with some modifications. Tetrahydrofuran (THF) is used as the solvent for CA. Its evaporation speed is adequately slow to ensure for uniform development of the polymer after casting on a glass plate to produce pure CA membrane. For pristine CA membrane fabrication, $1.5 \mathrm{~g}$ of CA powder is added to $14 \mathrm{ml} \mathrm{THF}$ and stirred for 24 hours using a magnetic bar. After 24 hours of mixing, the solution is sonicated for 30 minutes to eliminate air bubbles, and then is casted on a glass plate using a casting blade. The glass plate is covered and left 3 days on room temperature to ensure complete solvent evaporation.

For MMMs preparation, a loading $(2,4,6,8,10 \mathrm{wt} \%)$ of pristine KIT-6 is added to $14 \mathrm{ml}$ THF followed by 30 minutes ultrasonication. Then, CA powder is added and dissolved for 24 hours using a magnetic bar. After mixing, the solution is sonicated for 30 minutes to eliminate air bubbles, and then is casted on a glass plate using a casting blade. The glass plate is covered and left 3 days at room temperature to ensure complete solvent evaporation. The membranes produced are kept in desiccators for future usage.

\section{KIT-6 Characterization}

The crystalline structure of KIT-6 is determined by X-ray Diffraction (XRD, X'Pert ${ }^{3}$ Powder \& Empyrean, PANalytical) scanning from $0.8^{\circ}$ to $6^{\circ}$ theta. Functional groups in KIT-6 are determined by Fourier Transform Infrared Analysis (FTIR, Perkin Almer, Frontier). The samples are scanned for wavelength ranged from $4000-400 \mathrm{~cm}^{-1}$. The surface morphology of KIT-6 is revealed by using Scanning electron microscopy (SEM, Hitachi T3030). The thermal 
stability of KIT-6 is tested by TGA (Rigaku) with increasing rate of temperature $10^{\circ} \mathrm{C} / \mathrm{mins}$.

\section{Membrane Characterization}

The functional groups of pristine CA membrane and KIT-6 loaded MMMs are investigated by FTIR (Perkin Almer, Frontier). The samples are scanned for wavelength ranged from 4000-700 $\mathrm{cm}^{-1}$. Alterations in chemical and physical properties of materials are analyzed as a function of raising temperature by Thermal Gravimetric Analysis (TGA, Rigaku) with increasing rate of temperature $10^{\circ} \mathrm{C} /$ mins. The surface structures of the prepared membranes were analyzed by SEM (Hitachi T3030). The thickness measurement of CA membrane is determined by SEM (Hitachi T3030) cross sectional images of three different fabricated CA membrane with same preparation method.

\section{RESULTS AND DISCUSSION}

\section{Filler Characterization}

Figure 2 shows the powder XRD patterns of produced KIT-6 silica powder which exhibited intense peak diffractions at $1.09^{\circ}$. This shows that the sample has a highly ordered mesostructure with a 3D cubic Ia3d symmetry. The XRD pattern of the sample synthesized in current project is similar to the XRD pattern for KIT-6 reported by Ayad [13]. Figure 3 shows the FTIR spectrum of KIT-6. A number of characteristic bands are displayed by the FTIR spectrum of the KIT-6. The stretching vibration of hydrogen bonded silanol group $\mathrm{y}(\equiv \mathrm{Si}-\mathrm{OH})$ can be observed by characteristic band located at $3463.99 \mathrm{~cm}^{-1}$ [14]. The $\mathrm{O}-\mathrm{H}$ bending vibration mode indicated at about $1640.20 \mathrm{~cm}^{-1}$. The band at $1082.50 \mathrm{~cm}^{-1}$ and $803.54 \mathrm{~cm}^{-1}$ indicated to the anti-symmetric and symmetric stretching vibration of $\mathrm{Si}-\mathrm{O}-\mathrm{Si}$ groups, respectively [15].

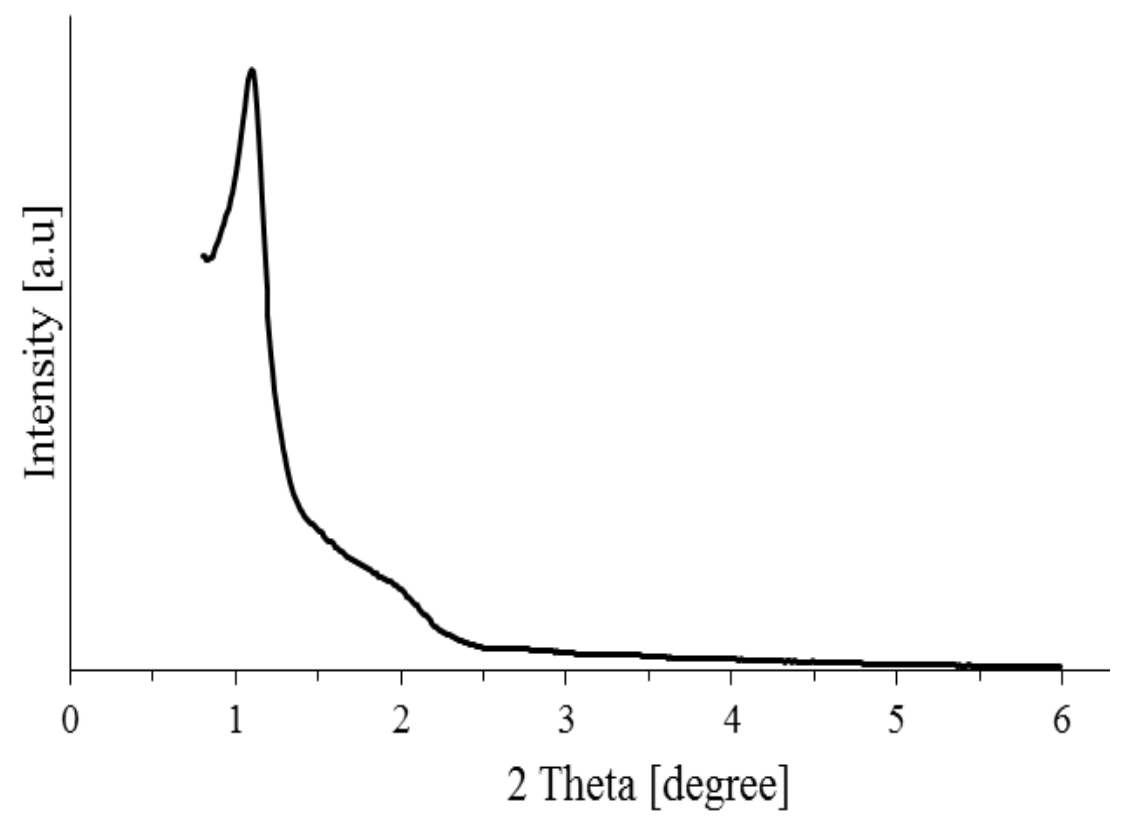

Figure 2. Low angle XRD patterns of KIT-6. 


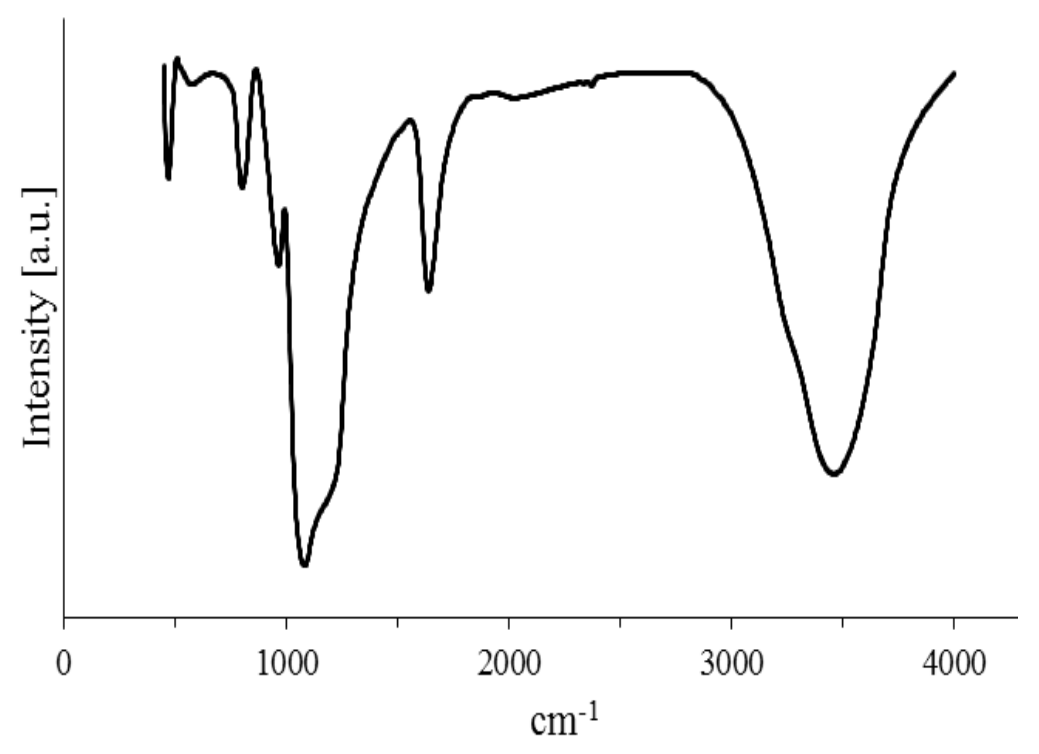

Figure 3. FTIR spectra of KIT-6.

The surface morphology of KIT- 6 with $1.5 \mathrm{k}$ resolution is presented in Figure 4 . The SEM image of KIT- 6 revealed the typical rock-like morphologies in current studies. Rock-like morphologies of KIT-6 with aggregation of different particles size are reported by Ayad [13].

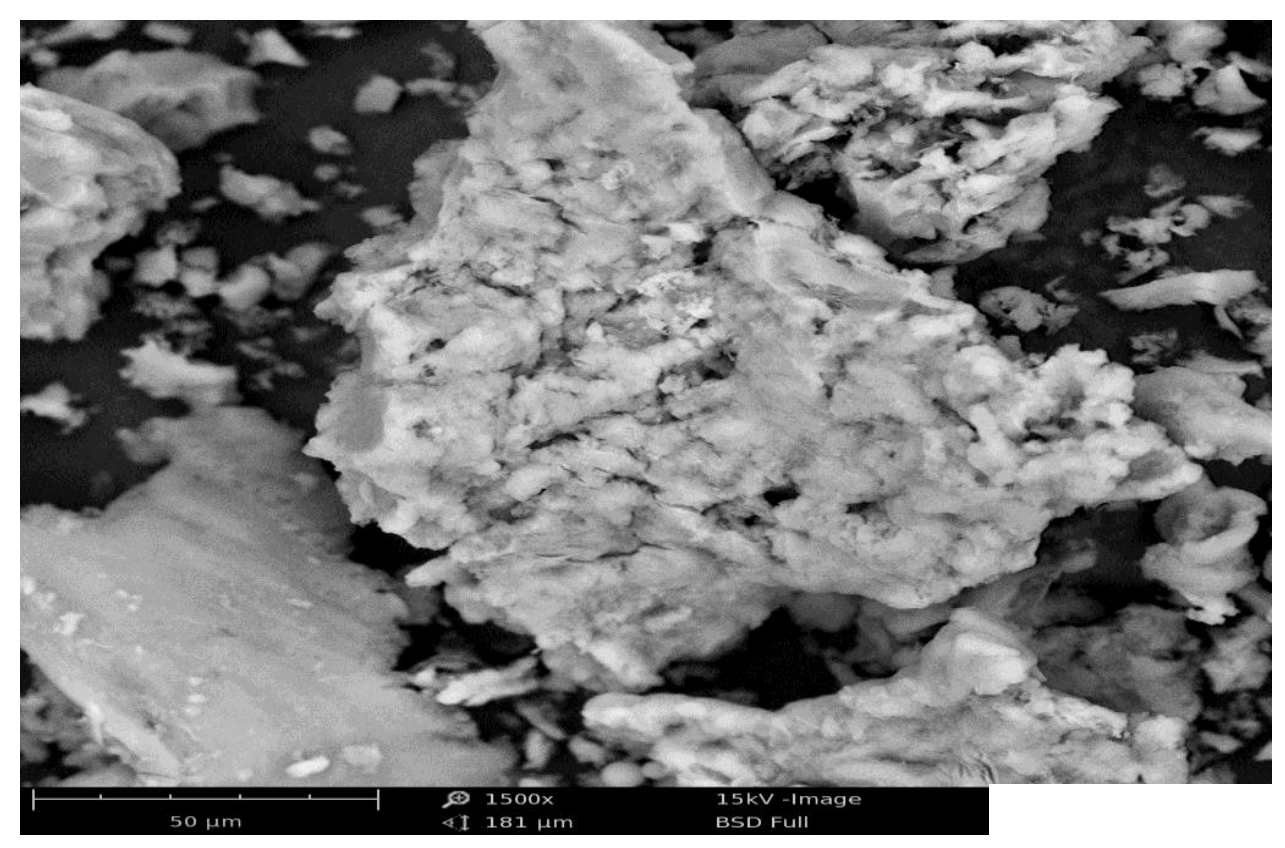

Figure 4. SEM image of pristine KIT-6.

Figure 5 shows the result of TGA analysis on KIT-6. It has been determined that the overall weight loss is $3.02 \%$. The weight loss process is occurred in 2 stages. In first stage, from $25^{\circ} \mathrm{C}$ to $330^{\circ} \mathrm{C}$, the evaporation of remaining absorbed water and the volatilization of the volatile matter take place. $1.52 \%$ of overall weight is loss in first stage. In second stage, from $330{ }^{\circ} \mathrm{C}$ to $700{ }^{\circ} \mathrm{C}$, KIT-6 has a weight loss of $1.5 \%$. These stages of weight loss are corresponded to Arthanareeswaran [15]. A high thermal stability has been shown by KIT-6 through TGA analysis [8]. 


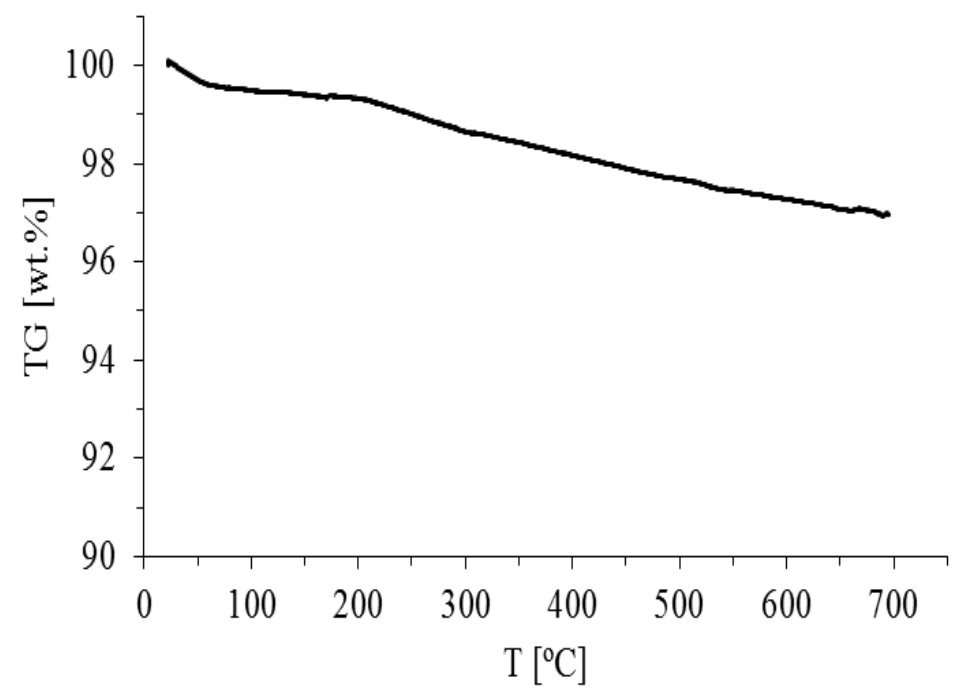

Figure 5. TGA curve of KIT-6.

\section{Membrane Characterization}

Figure 6 shows the FTIR spectrum of CA membrane and MMMs. A small broad band is shown in Figure 6 at $3458 \mathrm{~cm}^{-1}$ presents by pristine $\mathrm{CA}$ membrane indicated to $\mathrm{OH}-$ stretching vibrations of the hydroxyl group in the $\mathrm{CA}$ structure. Furthermore, $\mathrm{O}-\mathrm{H}$ bending vibration at about $1640 \mathrm{~cm}^{-1}$ is also found in the FTIR spectra for CA. The characteristic absorption bands of $\mathrm{CA}$ occur at $1733 \mathrm{~cm}^{-1}$ showed that $\mathrm{C}=\mathrm{O}$ stretching, $\mathrm{CH}_{3}$ symmetric deformation indicated at $1370 \mathrm{~cm}^{-1}$, acetate $\mathrm{C}-\mathrm{C}-\mathrm{O}$ stretching at $1222 \mathrm{~cm}^{-1}$ and $\mathrm{C}-\mathrm{O}$ stretching at $1034 \mathrm{~cm}^{-1}$ which are generally in agreement with Sanaeepur [16] and Benosmane [17]. At $1160 \mathrm{~cm}^{-1}$, stretching of the $\mathrm{C}-\mathrm{O}-$-bridge is observed which indicated the characteristic bands of the saccharide structure of $\mathrm{CA}$ and skeletal vibration involving the $\mathrm{C}-\mathrm{O}$ stretching indicated at $1034 \mathrm{~cm}^{-1}$. The $\beta$-linked glucan structure indicated at the absorption band at $904 \mathrm{~cm}^{-1}[16,18]$.

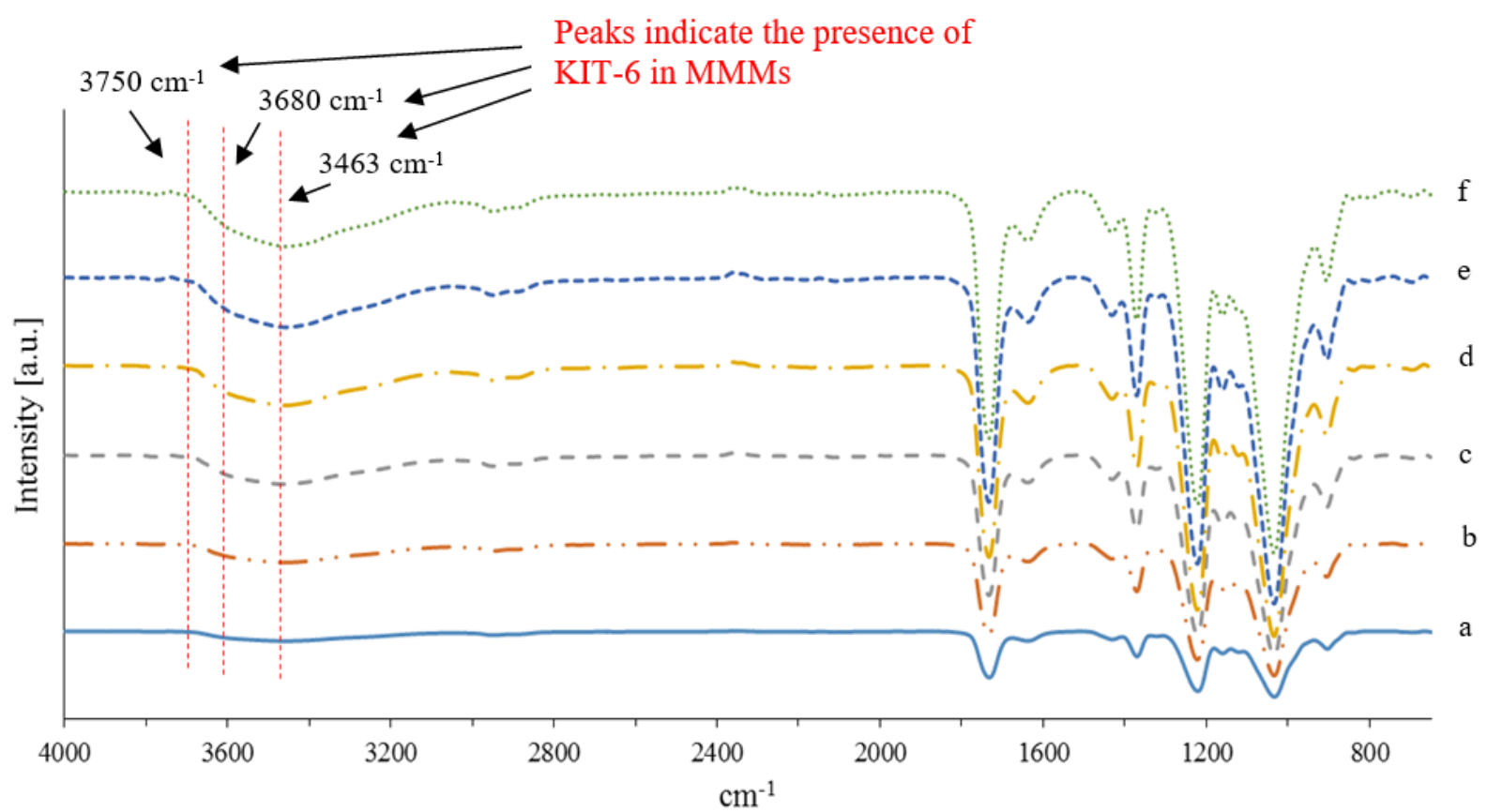

Figure 6. FTIR spectra of (a) pristine CA, (b) 2 wt \% KIT-6/CA, (c) 4wt \% KIT-6/CA, (d) 6wt \% KIT-6/CA, (e) 8wt \% KIT-6/CA and (f) 10wt \% KIT-6/CA MMMs. 
Other than these, it is observed that in MMMs, the overlapping of filler $\mathrm{y}(\equiv \mathrm{Si}-\mathrm{OH})$ characteristic band located at $3463 \mathrm{~cm}^{-1}$ with $\mathrm{OH}-$ stretching vibrations of CA at $3458 \mathrm{~cm}^{-1}$ occurred. The intensity of broad band around $3458-3463 \mathrm{~cm}^{-1}$ increased when the KIT- 6 loading increased from 2 to $10 \%$. The presence of KIT-6 silica can be confirmed by characteristic peak at around $3750 \mathrm{~cm}^{-1}$ which indicating freely vibrating $(\mathrm{SiO})_{3} \mathrm{Si}-\mathrm{OH}$ groups [19]. In addition, the small intensities of peaks around $3680 \mathrm{~cm}^{-1}$ showed the abundance of silanols engaged into hydrogen bonding [19].

Figure 7 showed the TGA curves of all membranes formed in current study. Generally, three major steps involved in the degradation of CA and MMMs. First and foremost, from $25^{\circ} \mathrm{C}$ to $330{ }^{\circ} \mathrm{C}$, volatilization of the volatile matter happened and absorbed water evaporated [15]. Second, the main thermal degradation of the cellulose acetate chains occurred at $330^{\circ} \mathrm{C}$ and finish at $450^{\circ} \mathrm{C}$. The final step, carbonization of the degraded products to ash occurred from $450^{\circ} \mathrm{C}$. Overall weight loss of $72.29-86.77 \%$ for all the membranes were observed. All the degradation steps were in agreement with Arthanareeswaran [15]. The stages of weight loss are corresponded to Arthanareeswaran [15].

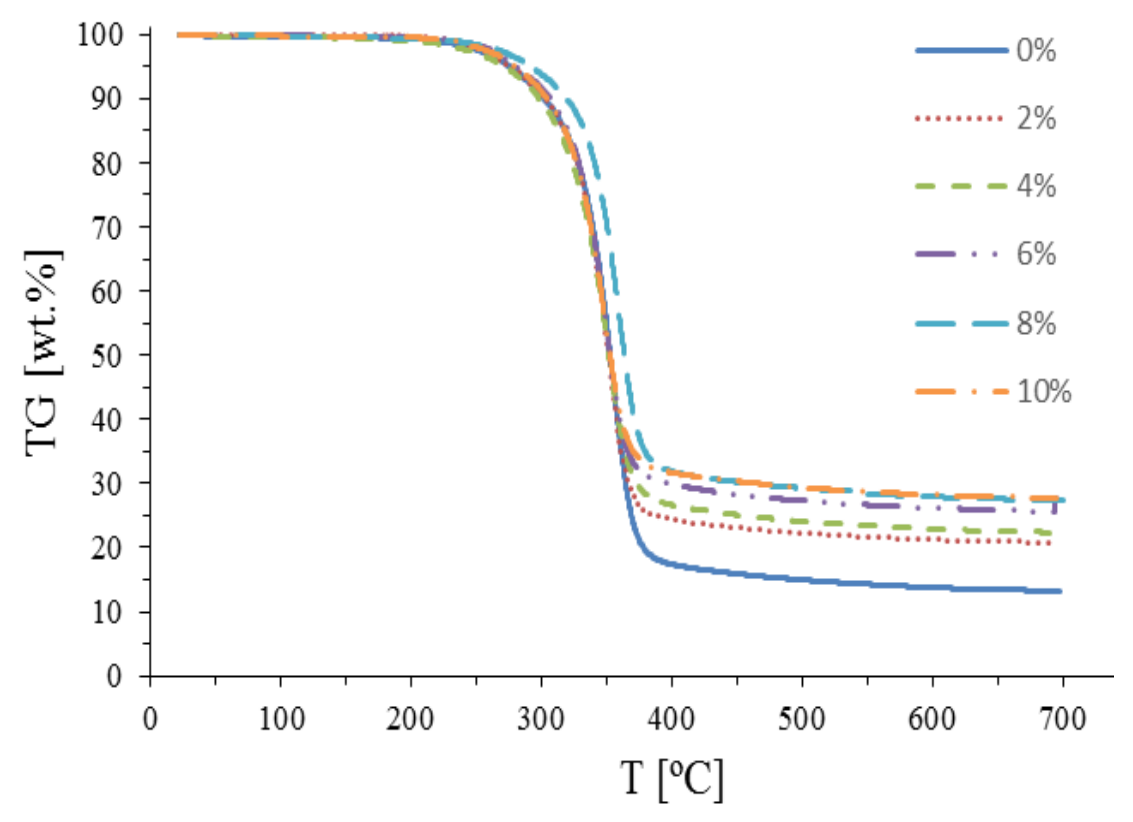

Figure 7. TGA curve of (a) pristine CA, (b) 2wt \% KIT-6/CA, (c) 4wt \% KIT-6/CA, (d) 6wt \% KIT-6/CA, (e) 8wt \% KIT-6/CA and (f) 10wt \% KIT-6/CA MMMs.

Figure 8 shows the SEM images of CA membrane and MMMs. It is shown from Figure 8 (a) that clear and smooth surface morphology is obtained for pristine CA membrane. However, white dots are found in the SEM images of MMMs indicate the present of KIT-6 in the MMMs. The number of dots increased with increasing filler incorporation percentage into CA polymer. Besides, well distribution and dispersion of KIT-6 in CA membrane can be observed from the allocation of these white dots. No assembled of white dots are found in the SEM images and this implies there could be no agglomeration of KIT-6 occurs in these membranes which is in agreement with the phenomenon reported by Tzi and Ching [20]. Furthermore, since KIT-6 possessing interpenetrating cylindrical pore system, the CA polymer chain may enter the KIT-6 pores and defect-free membrane could be produced [8]. 

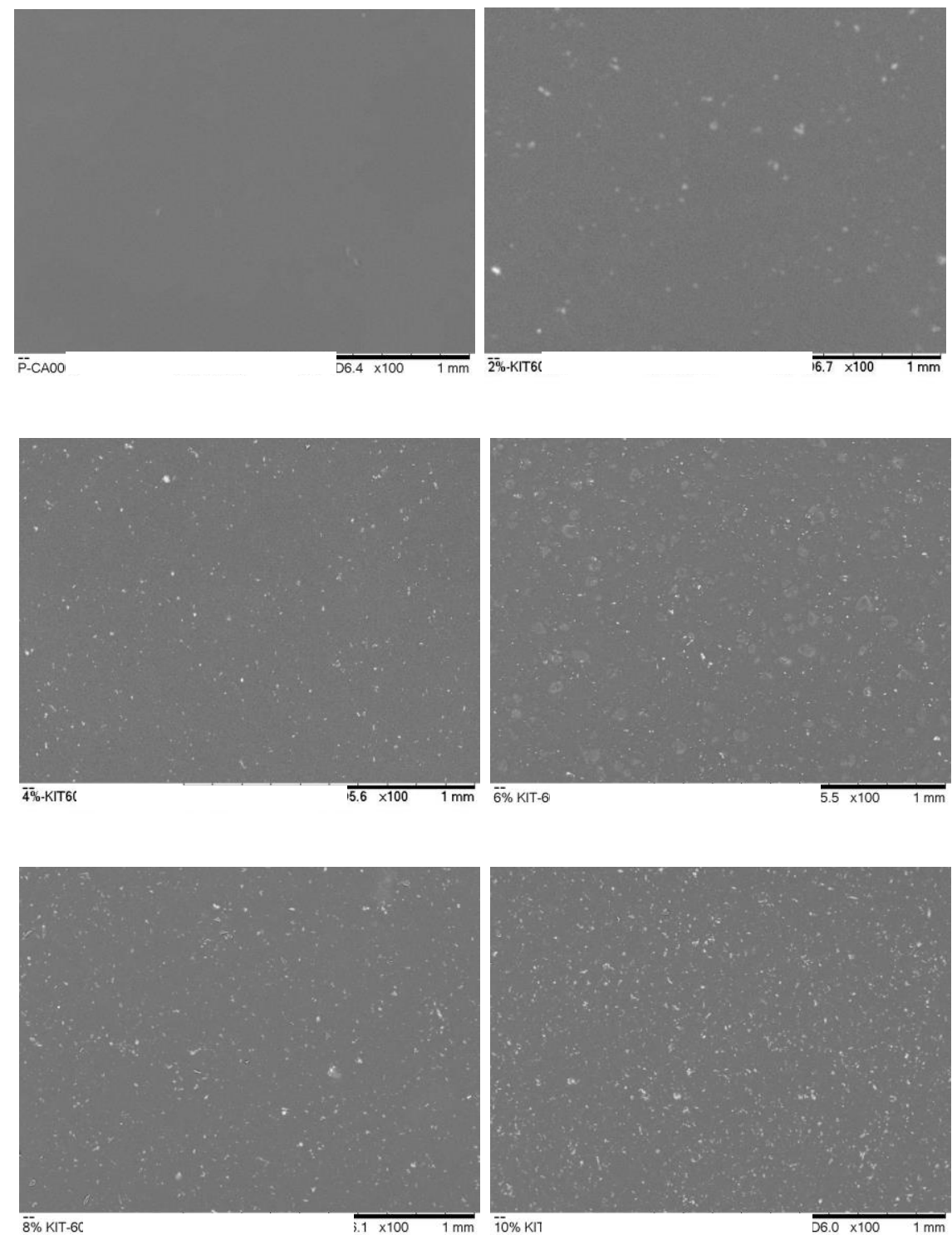

Figure 8. SEM surface images with 100 magnification resolution of (a) pristine CA, (b) $2 \mathrm{wt} \%$ KIT-6/CA, (c) 4wt \% KIT-6/CA, (d) 6wt \% KIT-6/CA, (e) 8wt \% KIT-6/CA and (f) 10wt \% KIT-6/CA.

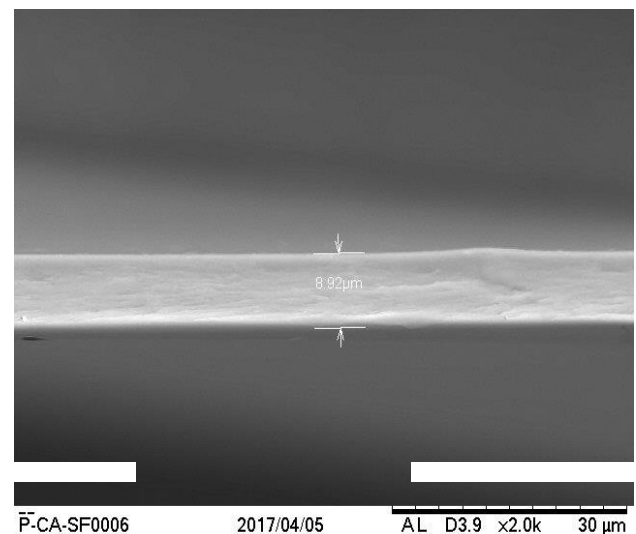

Figure 9. SEM cross sectional images of pristine CA membrane 
Figure 9 shows the SEM cross sectional view of the pristine CA membrane with measured membrane thickness of $8.92 \mu \mathrm{m}$. The procedures for preparing the pristine CA membrane were repeated for two more times and it was found that the preparation of pristine CA membranes could be repeated average membrane thickness of $9.18 \mu \mathrm{m}$ (standard deviation of $0.29 \mu \mathrm{m})$.

\section{CONCLUSIONS}

KIT-6 has been successfully synthesized which is confirmed by characteristic peaks appearing in FTIR spectrum and intense peak appearing in XRD. The KIT-6 is successfully incorporated as filler into the CA matrix, as confirmed by extra FTIR peaks and the presence of white dots in MMMs. It is found that there could be no agglomeration of KIT- 6 in the MMMs when the KIT-6 loading is increased from 2 to $10 \%$ of KIT-6 into CA matrix. The TGA curve of membranes suggested that not much changes on the thermal stability of most membranes by the incorporation of KIT-6 into CA matrix. The major contribution of the current work is successful fabrication of high quality MMMs with no obvious KIT-6 agglomeration observed. It is recommended to investigate the gas permeation and separation performance of the high quality fabricated MMMs from current study.

\section{ACKNOWLEDGEMENTS}

The authors acknowledge the support provided by LRGS grant (grant number: 304/PJKIMIA/6050296/U124). The financial and technical support from LRGS grant (cost centre: 0153AB-L12), Institute of Contaminant Management, Universiti Teknologi PETRONAS and $\mathrm{CO}_{2}$ Research Centre (CO2RES), Universiti Teknologi PETRONAS are also acknowledged.

\section{REFERENCES}

[1] Karimi MB, Hassanajili S. Short fiber/polyurethane composite membrane for gas separation. Journal of Membrane Science. 2017;543:40-48

[2] Castel C, Wang L, Corriou JP, Favre E. Steady vs unsteady membrane gas separation processes. Chemical Engineering Science. Retrieved from https://doi.org/10.1016/j.ces.2018.03.013

[3] Kishor R, Ghoshal AK. APTES grafted ordered mesoporous silica KIT-6 for $\mathrm{CO}_{2}$ adsorption. Journal of Chemical Engineering. 2015;262:882-890.

[4] Bai Y, Bai Q. Corrosion and corroded pipelines. Retrieved from http://dx.doi.org/10.1016/B978-0-12-394432-0.00001-9

[5] Ahmad AL, Jawad ZA, Low SC, Zein SHS. A cellulose acetate/multi-walled carbon nanotube mixed matrix membrane for $\mathrm{CO}_{2} / \mathrm{N}_{2}$ separation. Journal of Membrane Science. 2014;451:55-66.

[6] Rezakazemi M, Sadrzadeh M, Matsuura T. Thermally stable polymers for advanced high-performance gas separation membranes. Progress in Energy and Combustion Science. 2018;66:1-41.

[7] Lee S, Park SC, Kim TY, Kang SW, Kang YS. Direct molecular interaction of $\mathrm{CO}_{2}$ with KTFSI dissolved in Pebax 2533 and their use in facilitated $\mathrm{CO}_{2}$ transport membranes. Journal of Membrane Science. 2018;548:358-362.

[8] Wang JH, Li Y, Zhang ZS, Hao ZP. Mesoporous KIT-6 silica-polydimethylsiloxane (PDMS) mixed matrix membranes for gas separation. Journal of Material Chemistry Academy. 2015;3:8650-8658. 
[9] Yavaria M, Okamotob Y, Lina H. The role of halogens in polychlorotrifluoroethylene (PCTFE) in membrane gas separations. Journal of Membrane Science. 2018;548:380-389.

[10] Kim S, Marand E. High permeability nano-composite membranes based on mesoporous MCM-41 nanoparticles in a polysulfone matrix. Microporous and Mesoporous Materials. 2008;114:129-136.

[11] Zamani C, Illa X, Abdollahzadeh-Ghom S, Morante JR, Rodri'guez AR. Mesoporous Silica: A Suitable Adsorbent for Amines. Nanoscale Res Lett. 2009;4:1303-1308.

[12] Kim WG, Lee JS, Bucknall DG, Koros WJ, Nair S. Nanoporous layered silicate AMH-3/cellulose acetate nanocomposite membranes for gas separations. Journal of Membrane Science. 2013;441:129-136.

[13] Ayad MM, Salahuddin NA, El-Nasr AA, Torad NL. Amine-functionalized mesoporous silica KIT-6 as a controlled release drug delivery carrier. Microporous and Mesoporous Materials. 2016;229:166-177.

[14] Nigar, H. (2016). Amine-Functionalized Mesoporous Silica: A material capable of $\mathrm{CO}_{2}$ adsorption and fast regeneration by microwave heating. American Institute of Chemical Engineers. 2016;62:547-555.

[15] Arthanareeswaran G, Thanikaivelan P, Srinivasn K, Mohan D, Rajendran M. Synthesis, characterization and thermal studies on cellulose acetate membranes with additive. European Polymer Journal. 2004;40:2153-2159.

[16] Sanaeepura H, Kargaria A, Nasernejad B, Amooghin AE, Omidkhah M. A novel CO ${ }^{2+}$ exchanged zeolite Y/cellulose acetate mixed matrix membrane for $\mathrm{CO}_{2} / \mathrm{N}_{2}$ separation. Journal of the Taiwan Institute of Chemical Engineers. 2016;60:403-413.

[17] Benosmane N, Guedioura B, Hamdi SM, Hamdi M, Boutemeur B. Preparation, characterization and thermal studies of polymer inclusion cellulose acetate membrane with calix[4] resorcinarenes as carriers. Materials Science and Engineering: C. 2010;30:860-867.

[18] Dogan H, Hilmioglu ND. Zeolite-filled regenerated cellulose membranes for pervaporative dehydration of glycerol. Vacuum. 2010;84:1123-1132.

[19] Majda D, Tarach K, Marek KG, Zym M, Napruszewska BD, Zimowska M, Serwicka EM. Thermoporosimetry of n-alkanes for characterization of mesoporous SBA-15 silicas-Towards deeper understanding the effect of the probe liquid nature. Microporous and Mesoporous Materials. (2016;226:25-33.

[20] Tzi ECN, Ching OP. Surface modification of AMH-3 for development of mixed matrix membranes. Procedia Engineering. 2016;148:86 - 92 